\title{
Christine Ferlampin-acher, 'Merveilles' et topique merveilleuse dans les romans médiévaux
}

\section{Maria Colombo Timelli}

\section{(2) OpenEdition}

1 Journals

\section{Édition électronique}

URL : http://journals.openedition.org/studifrancesi/32787

DOI : 10.4000/studifrancesi.32787

ISSN : 2421-5856

Éditeur

Rosenberg \& Sellier

\section{Édition imprimée}

Date de publication : 1 décembre 2005

Pagination : 612

ISSN : 0039-2944

\section{Référence électronique}

Maria Colombo Timelli, « Christine Ferlampin-acher, 'Merveilles' et topique merveilleuse dans les romans médiévaux », Studi Francesi [En ligne], 147 (XLX | III) | 2005, mis en ligne le 30 novembre 2015, consulté le 20 avril 2021. URL : http://journals.openedition.org/studifrancesi/32787 ; DOI : https://doi.org/ 10.4000/studifrancesi.32787

Ce document a été généré automatiquement le 20 avril 2021.

\section{(c) $($ ) $\odot$}

Studi Francesi è distribuita con Licenza Creative Commons Attribuzione - Non commerciale - Non opere derivate 4.0 Internazionale. 


\title{
Christine Ferlampin-acher, 'Merveilles' et topique merveilleuse dans les romans médiévaux
}

\author{
Maria Colombo Timelli
}

\section{RÉFÉRENCE}

CHRISTINE FERLAMPIN-ACHER, 'Merveilles' et topique merveilleuse dans les romans médiévaux, Paris, Champion, 2004 («Nouvelle bibliothèque du Moyen Âge», 66), pp. 567.

1 Christine Ferlampin-Acher étudie l'inscription d'une topique merveilleuse dans les romans, en vers et en prose, du Moyen Âge français, à partir d'un important corpus de textes dont la liste est donnée en bibliographie (cf. pp. 525-30). Elle aborde préalablement la question de la spécificité même du 'merveilleux', qui se définit comme une rupture avec la norme / le réel selon un processus reconnaissable allant d'une vision à l'étonnement suscité par celle-ci, puis à un questionnement amenant une pluralité de réponses (chapitre I, Définition, pp. 9-24). Il s'agit ensuite de reconnaître les indices textuels signalant l'émergence de la 'merveille'; le mot à lui seul ne suffisant évidemment pas pour faire naître le merveilleux, on relèvera des combinaisons lexicales ainsi que des procédés syntaxiques et stylistiques: amplificatio, tentant de combler l'impossibilité de dire, écriture surchargée, et, à l'opposé, praeteritio (chapitre II, Vers une topique du merveilleux, pp. 25-90). La perception de la merveille s'avère problématique: présentée à travers le regard d'un personnage, elle est en même temps difficile à voir et périlleuse à regarder. Qu'elle concerne une personne, un lieu ou un objet, elle donne pourtant lieu à des développements textuels: morceau de bravoure ou à peine amorcée, la description annonce les questions qui vont se poser (chapitre III, Le regard empêché, pp. 91-170). La parole suscitée par la merveille est polymorphe: pensée, monologue intérieur, monologue articulé, discours direct ou indirect, quelle que soit son expression, elle donne accès à l'intériorité du personnage. Nombreuses et diverses, les questions portent sur l'origine du merveilleux et sur sa senefiance et donnent lieu à 
une pluralité de réponses polysémiques. Les interprétations proposées s'avèrent en effet nécessairement décevantes ou différées: dans la plupart des cas, le sens de la merveille est suspendu, dans la mesure où il est impossible de l'enfermer dans une question suivie d'une réponse univoque (chapitre IV, La formulation romanesque du merveilleux: polyphonie et polysémie, pp. 171-266).

Une fois défini le schéma narratif centré sur la merveille, C. Ferlampin-Acher analyse le rapport étroit que celle-ci semble entretenir avec le genre romanesque. Elle montre ainsi, d'une part, la multiplicité et le gommage des sources des romans (allant de la réalité contemporaine aux représentations figuratives, des sources orales / folkloriques aux sources écrites, narratives ou non), d'autre part les spécificités de la structure romanesque (caractère composite des romans, conjointure interne et entrelacement, inachèvement et clôture problématique, ouverture et conjointure externe) et l'affirmation de la subjectivité (des personnages, du narrateur, du lecteur): autant d'éléments qui concourent à l'émergence et à l'expression du merveilleux (chapitre $\mathrm{V}$, 'Merveilleux' et genre romanesque, pp. 267-380). Un dernier chapitre (Parcours de la tradition romanesque, pp. 381-519) s'interroge sur l'évolution du phénomène et sur le rapport éventuel entre le merveilleux d'une part et la forme, vers ou prose, de l'autre. Sans pouvoir prendre en compte l'ensemble de la production romanesque médiévale, C. Ferlampin-Acher en arrive néanmoins à reconnaître les signes de modifications progressives: en germe dans les romans antiques, le merveilleux s'épanouit dans les romans de Chrétien de Troyes, pour subir un processus de rationalisation dans les cycles et sommes en prose du XIII siècle (Lancelot et Tristan).

3 Très significativement, les pages conclusives portent le titre d'Ouverture (pp. 521-524), le merveilleux suscitant bien d'autres questions: le rapport avec les images illustrant le texte, l'insertion éventuelle du merveilleux dans les romans dits 'réalistes', sa présence dans des genres autres que le roman. Autant de problèmes que C. Ferlampin-Acher se propose d'aborder dans un livre à venir.

Une bibliographie raisonnée, très riche, est donnée en complément (pp. 525-556), ainsi qu'un Index des cuvres et des auteurs du Moyen Âge cités (pp. 557-561).

5 Il s'agit d'une étude sérieuse et stimulante, qui n'oublie pas les œuvres dans leur dimension concrète (rédactions différentes, variantes, 'mouvance' des textes) outre que littéraire: à partir d'un ensemble imposant de données, ce beau livre constitue un essai de synthèse remarquable. 